\title{
Computer Planning and Skull Reconstruction in a Removal of a Giant Intraosseal Meningeoma
}

\author{
ĐurićKS*, PašalićI, Barl P, Domazet I and Mrak G \\ Department of Neurosurgery, University Hospital Center Zagreb, School of Medicine, Croatia
}

Submission: March 26, 2018; Published: July 18, 2018

*Corresponding author: Kresimir S Duric, Department of Neurosurgery,University Hospital Center Zagreb, School of Medicine, Zagreb, Croatia, Email: kresoduric@yahoo.com

\section{Letterto Editor}

Neoplastic processes involving major parts of the neurocranium indicated for surgical treatment present a challenge due to the complex geometry which needs to be reconstructed. The current approach to the removal of such lesions entails resection and reconstruction during the same surgery. Reconstruction using prefabricated implants is mandatory in order to meet current high cosmetic standards. The planning of such procedures is demanding since preoperative imaging methods do not show the defects which meet the resection requirements. These procedures include computer planning of the resection margins and production of individually tailored implants. To mark the resection margins neuronavigation and templates may be used. Advancements in 3D printing technology as well as medical imaging processing software have significantly contributed to the popularization of this type of therapeutic approach. Here we present a case where a gigantintraosseal meningioma was successfully removed and during the same surgery a cosmetically correct reconstruction of the cranium was performed with the use of computer technology and $3 \mathrm{D}$ printing.

\section{Case}

A healthy 64-year-old woman presented with a head MSCT showing a tumour within more than half of the neurocranium, tumour spread in the periosteum, and a small intradural lesion (Figure1). The head MR did not yield any additional information. In view of the large infiltration area (Figure1), as well as the specific speculated shape of the changes on the external table and the extent of the skull infiltration, we decided to do a biopsy first. The biopsy revealed a WHO grade I meningioma. Based on the biopsy findings, we decided to perform a radical resection of the tumour. In view of the tumour size and the complexity of calvarial reconstruction, we decided to use computer technology to plan the extent of the resection along with 3-dimensional printing technology to create the template and cast needed for the production of the implant. Thin-slice $(1,25 \mathrm{~mm})$ MSCT was used to plan the tumour resection, and free 3D Slicer software to determine the resection margins in all three cross-sections (axial, sagittal, and coronal)[1]. The computer reconstruction of the cranial defect as well as the template and cast for the implant were created with the use of Solid Works software[2]. The template and cast were produced by means of a Stratasys Objet30 OrthoDesk 3D printer from MED610 material. The template and cast underwent cold sterilization before the surgery.

\section{Operative Procedure}

After induction of general anaesthesia, the patient was placed into the "Concorde" position and her head was fixed with a Mayfield ${ }^{\mathrm{TM}}$ head clamp. The operation site was prepared in the standard manner. A skin incision was made to expose the whole area of the bone affected by the tumour. The template was placed and the craniotomy margins were outlined by a highspeed drill. The tumour was resisted in a piecemeal fashion up to the previously defined margins. During the tumour resection the patient had an episode of air embolism. Upon stabilization of the patient the operative procedure was resumed. The implant for the reconstruction of the defect was produced from Palacos (Codman, CRANIOPLASITC ${ }^{\text {тм }}$ Kit), and the polymerization procedure was completed intraoperatively in the cast, resulting in a 3-mm biocompatible implant. The dura was resected at the intradural part of the tumour, but upon resection an endplaque meningioma was revealed, and thus resection of the durra was completed in the full circumference of the resected bone tumour. The dural defect was reconstructed with the use of dura substitute. The implant was placed and fixed with titanium plates. The soft tissues were sutured in layers. Upon completion of the procedure the patient was taken to the ICU and awakens the same afternoon. The postoperative period proceeded uneventfully, and more than satisfactory clinical and cosmetic outcomes were achieved.

\section{Discussion}

Recently, Tehli et al. [3] have published four cases of monostotic-type fibrous dysplasia where tumour resection and bone defect reconstruction were performed in one act 
with excellent functional and cosmetic outcomes. This was achieved with the use of computer technology in the planning of the resection margins, based on which the templates and implants were created. Titanium and 3D manufacturing technology were used.Michael Bruneau et al. $[4,5]$ reported how to perform neuronavigation-assisted bone tumour resection and reconstruction with a prefabricated implant in a single act. They used an OsirisX tool included in the freeware for the planning of resection margins.In this case we used free 3D Slicer software to plan the extent of the resection [1]. Both the finalization of the virtual model and the reconstruction of the defect according to the principle of symmetry were done with the use of the Solid Works software[2]. Based on the computer-generated defect reconstruction and with the use of 3D printing technology and biocompatible material a cast was fabricated.

The polymerization procedure of the material standard used at our Clinic for the reconstruction of cranial defects was completed intraoperatively within the cast. The template was produced from the same material using the same technology.
We consider that the method described here resulted in a satisfactory level of accuracy of the cranial reconstruction, which is a prerequisite of a good cosmetic and clinical outcome. The 3D printing technology applied in this case is significantly cheaper than 3D metal printing and hence more available in routine clinical practice. Studies published so far report excellent results for implants obtained by this (negative-positive) method [6-8]. We believe that our case represents an economical method of one-stage neurocranial tumour resection and reconstruction (Figure 1). A possible disadvantage of using plastic templates is their potential for distortion, which is less likely to occur with metal templates. In our case, the bone biopsy site was utilized to verify the accuracy of template positioning. Based on our experience, we can recommend the use of neuronavigationassisted resection margin planning or template position verification. We believe that the described case speaks in favor of the effectiveness of the use of plastic 3D printing technology used for definition of surgical resection margins as well for defect reconstruction in the field of neurosurgery.

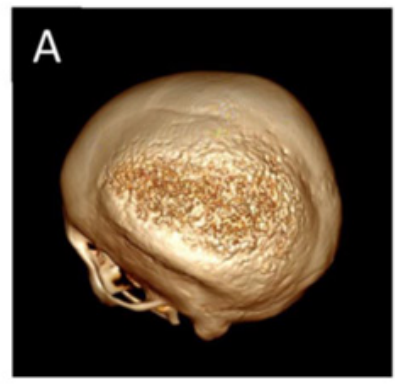

A

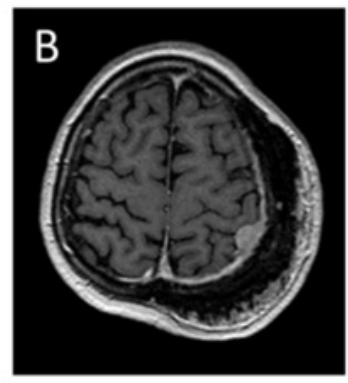

B

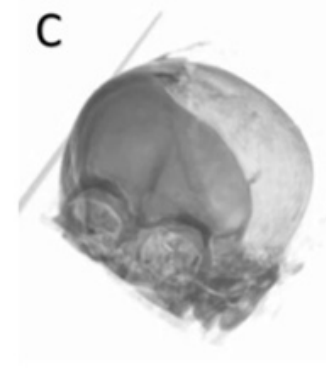

C

Figure 1: A head MSCT showing a tumor within more than half of the neurocranium, tumor spread in the periosteum, and a small intradural lesion.

\section{Patient Consent}

The patient whose case is reported above voluntarily agreed to the use of the described method, and consented to the publication of this article. The institutional Ethics Committee approved a study titled "Feasibility study of cranial defect reconstruction with the use of a previously manufactured cast", and the case reported above represents a specific part of this study.

\section{Acknowledgement}

We would like to thank A. Melada, whose efforts significantly contributed to the implementation of 3D printing technology at our institution. We also wish to thank Josip Rauker and the Medical 3D Design Company, who donated their time and the material for the manufacturing of the template and cast. Finally, our sincere thanks to Aleksandra Žmegač Horvat from the University Of Zagreb School Of Medicine for the English translation of our manuscript.
2. http://www.solidworks.com

3. Tehli O, Dursun AM, Temiz C, Solmaz I, Kural C (2015) Computer-based surgical planning and custom-made titanium implants for cranial fibrous dysplasia. Neurosurgery 11(2): 213-219.

4. Bruneau M, Kamouni R, Schoovaerts F, Pouleau HB, De Witte O (2015) Simultaneous image-guided skull bone tumour resection and reconstruction with a preconstructed prosthesis based on an osiri $\mathrm{x}$ virtual resection. Neurosurgery 11(4): 484-490.

5. http://www.osirix-viewer.com

6. Rotaru H, Stan H, Florian IS, Schumacher R, Park YT (2012) Cranioplasty with custom-made implants: analyzing the cases of 10 patients. J Oral Maxillofac Surg 70(2): e169-e176.

7. Kim BJ, Hong KS, Park KJ, Park DH, Chung YG (2012) Customized cranioplasty implants using three-dimensional printers and polymethyl-methacrylate casting. J Korean Neurosurg Soc 52(6): 541546.

8. Fiaschi P, Pavanello M, Imperato A, Dallolio V, Accogli A (2016) Surgical results of cranioplasty with a polymethylmethacrylate customized cranial implant in pediatric patients: a single-center experience. J Neurosurg Pediatr 17(6): 705-710.

\section{References}

1. http://www.slicer.org 
This work is licensed under Creative Commons Attribution 4.0 Licens

DOI: 10.19080/OAJNN.2018.08.555728
Your next submission with Juniper Publishers will reach you the below assets

- Quality Editorial service

- Swift Peer Review

- Reprints availability

- E-prints Service

- Manuscript Podcast for convenient understanding

- Global attainment for your research

- Manuscript accessibility in different formats ( Pdf, E-pub, Full Text, Audio)

- Unceasing customer service

Track the below URL for one-step submission https://juniperpublishers.com/online-submission.php 